\title{
Drug utilization and antibiotic use in the primary health care centres in Sharjah
}

Mohamed Yousif Hasan, ${ }^{1}$ Mandira Das ${ }^{2}$ and Fatema Mourad ${ }^{3}$

$$
\begin{aligned}
& \text { استعمال الأدوية والمضادات الميوية في مراكز الرعاية الصحية الأولية في الشارقة }
\end{aligned}
$$

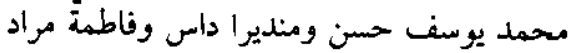

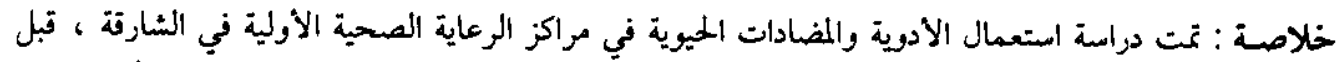

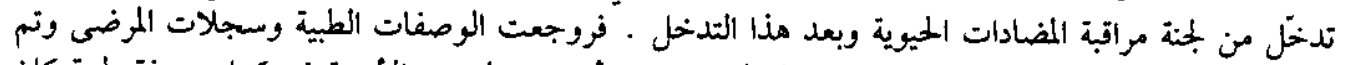

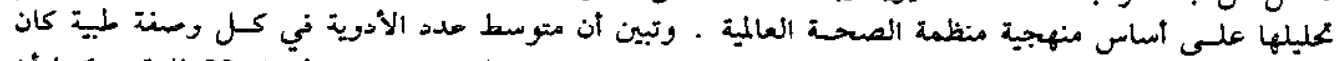

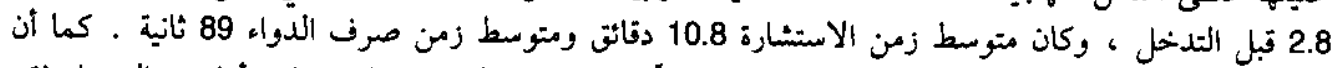

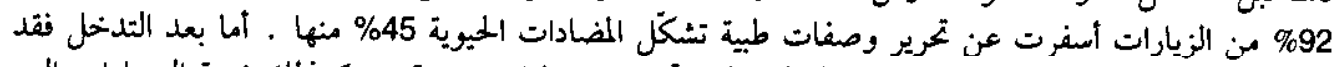

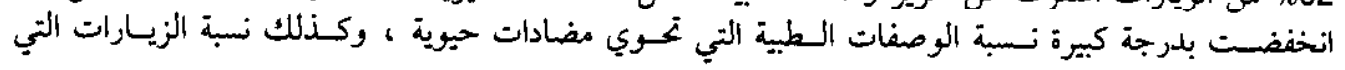

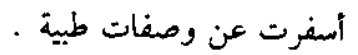

ABSTRACT Drug utilization and antibiotic use in the primary health care centres in Sharjah were studied before and after an intervention by the Antibiotics Control Committee. Prescriptions and patient records were reviewod and analysed besed on World Hoalth Organization mothodology. Before intervention, the average number of drugs per prescription was 2.8 , the average consultation time was 10.8 minutes, the average dispensing time was 89 seconds and $92 \%$ of visits resulted in a prescription, of which antibiotics constituted $45 \%$. Following intervention, the percentage of prescriptions with antibiotics and the percentage of visits resulting in a prescription were significantly reduced.

L'utilisation des médicaments et des antibiotiques dans les centres de soins de santé prìmaires à Sarjah

RESUME L'utilisation des médicaments et des antibiotiques dans les centres de soins de santé primaires à Sarjah a été étudiéo avant et après une intervention rbalisée par le Comité de contrôle des antibiotiques. Les ordonnances et les dossiers des patients ont été passés en revue et analysés en utilisant la méthodologie de l'Organisation mondiale de la Santé. Avant l'intervention, le nombre moyen de médicaments par ordonnance s'élevait à 2,8, la durée moyenne d'une consultation était de 10,8 minutes, la durée moyenne de délivrance des médicaments était de 89 secondes et $92 \%$ des visites se terminaient par une prescription de médicaments dont $45 \%$ étaient des antibiotiques. Suite à l'intervention, le pourcentage des ordonnances comportant des antibiotiques et le pourcentage de consultations se terminant par une prescription de médicaments ont considérablement diminué.

'Department of Pharmacology: ${ }^{2}$ Department of Medical Education, Faculty of Medicine, United Arab Emirates University, Al-Ain, United Arab Emirates.

${ }^{3}$ Pharmacy Department. Shariah Medical District. Ministry of Health. Sharjah. United Arab Emirates. Received: 22/12/96; accepted: 11/05/97 


\section{Introduction}

Drug therapy is considered to be a major component of patient management in health care settings, including primary health care. Although the benefits gained by patients from pharmacological interventions are valuable, the risks of drugs per se and the consequences of inappropriate use cannot be overlooked. Additionally, the cost of medicine is a matter of great concern in both developing and industrialized countries. Of the various classes of drugs, antibiotics receive special attention as more money is spent on them than many other drugs [1]. Some antibiotics also have specific side-effects and extensive antibiotic use can lead to the development of resistant microorganisms [2].

Studies on the effectiveness of intervention techniques on the quality of health care and prescribing behaviour of physicians in developing countries are greatly needed. However, guidelines for rational prescribing are either not available or not effectively implemented in many developing countries. In 1995, Hogerzell described several strategies which have been tried, mostly in industrialized countries, to promote rational prescribing [3]. These are: a) educational strategies such as printed material, seminars, bulletins and face-to-face methods; b) managerial methods referring to various restrictions on prescribing; c) regulatory measures including procedures to evaluate critically drugs and product information. Hospital formularies and special committees for treatment of infections have also been reported to be useful in reducing the misuse of drugs [4].

The government of the United Arab Emirates (UAE) has adopted the primary health care (PHC) approach as the longterm strategy for providing health care to all residents of the country [5]. Access to secondary and tertiary care cannot be acquired easily without referral from PHC centres or emergency services. PHC centres provide facilities for disease prevention and treatment, promotion of health and rehabilitation. Health care facilities in the UAE have developed tremendously in the past 25 years following the oil-related economic boom. Several new strategies related to health care have been formulated by the UAE Ministry of Health (MOH) since its inception in 1972 and the cost of health care for citizens and residents of the UAE is heavily subsidized by the government.

Sharjah is one of the seven emirates in the UAE with an approximate population of 400 000. At present there are six primary health care centres and two hospitals under UAE-MOH in the Sharjah central city, where the population is approximately 320000 . With regard to regulations related to health care, the Sharjah Medical District follows the guldelines of the federal government. However, several local regulatory bodies have been formed to ensure that drug availability and prescribing in the District conform to the highest contemporary standards. In 1995, the Antibiotics Control Committee $(\mathrm{ACC}$ ) was formed to provide guidelines to practising physicians about the use and abuse of antibiotics. The committee is responsible for analysing the pattern of antibiotic prescriptions and preparing guidelines for antibiotic use within the Sharjah Medical District. The committee is composed of the heads of the departments of surgery, paediatrics, medicine and nursing and the director of primary health care centres in Sharjah. The committee also includes the chief pharmacist in the region, a clinical pharmacologist and a microbiologist as members. In May 1995, the committee produced guidelines related to 
antibiotics that were circulated to all physicians in the District. The guidelines emphasized the following: 1) the presence of up-to-date information about all antibiotics in each PHC centre and hospital; 2) methods and strategies for choosing appropriate antibiotics for a specific disease condition; 3) the establishment of antibiotics subcommittecs in each health care facility for auditing antibiotics use. The information package contained articles about the use and abuse of antibiotics worldwide. Meetings were organized with the physicians of the District to discuss the status of antibiotics and the details of the guidelines.

In this paper we report the results of the following investigations:

- the quality of health care in relation to pharmaceutical services and prescribing behaviour of primary health care physicians in the six PHC centres in the Sharjah Medical District;

- the impact of an intervention on the antibiotics prescribing behaviour of the PHC physicians in the same centres.

\section{Methodology}

\section{Drug-use indicators}

Twelve core quantitative indicators to measure some key aspects of prescribing and the quality of health care have been developed and tested by the WHO Action Programme on Essential Drugs and the International Network for the Rational Use of Drugs [6]. All these drug-use indicators were included in our study except one --patient knowledge of correct dosage. An additional indicator, the percentage share of each antibiotic, i.e. the proportionate distribution of antibiotics prescribed, was included to identify the frequency of individual antibiotics prescribed. The percentage of visits resulting in a prescription was also analysed to indicate the incidence of treatment without prescription. Detailed information about how to investigate drug use in health care facilities is found in the WHO manual [6].

\section{Sampling frame}

The study was condueted in the six PHC centres of Sharjah Medical District. Information related to patient care and health facility indicators were collected prospectively during the patients' visits to the centres. Consultation time (expressed in minutes) was calculated by dividing the total time spent for a series of consultations by the number of consultations. The average dispensing time (expressed in seconds) was measured by dividing the total time for dispensing drugs to a series of patients who received the drugs by the number of these patients. The percentage of drugs actually dispensed and adequately labelled were checked after the patients had left the pharmacies of the PHC centres. A record was maintained about the availability of key drugs and a current copy of the PHC drug formulary during the time of the study. The prospective study started in January 1995 and was completed in September 1995. To measure prescribing indicators, a retrospective study was done using data from patient records and prescriptions. Patient records and prescriptions from January to September 1995 were included for analysis.

The Antibiotics Control Committee (ACC) guidelines were made available to physicians in May 1995. During this period, several activitles were organized by the $\mathrm{ACC}$ in their drive to increase awareness of the problems of irrational prescribing among the health care professionals in Sharjah. For all drug-use indicators, information obtained from January to April 1995 
Table 1 Number of patients and patient records/prescriptlons included in the study in the six PHC centres

\begin{tabular}{|c|c|c|c|c|c|}
\hline \multirow[t]{2}{*}{ PHC centre } & \multicolumn{2}{|c|}{$\begin{array}{l}\text { Number of patients in } \\
\text { the prospective study }\end{array}$} & \multicolumn{2}{|c|}{$\begin{array}{l}\text { Number of records in } \\
\text { the retrospective study }\end{array}$} & \multirow{2}{*}{$\begin{array}{l}\text { Number of visits to } \\
\text { the centres during } \\
\text { the study period }\end{array}$} \\
\hline & Before & After & Before & After & \\
\hline 1 & 80 & 80 & 400 & 400 & 16352 \\
\hline 2 & 160 & 160 & 800 & 800 & 31283 \\
\hline 3 & 200 & 200 & 1000 & 1000 & 40326 \\
\hline 4 & 240 & 240 & 1200 & 1200 & 45979 \\
\hline 5 & 240 & 240 & 1200 & 1200 & 47841 \\
\hline 6 & 280 & 280 & 1400 & 1400 & 57136 \\
\hline Total & 1200 & 1200 & 6000 & 6000 & 238917 \\
\hline
\end{tabular}

was considered as information before policy intervention, and that from June onwards was considered as information after intervention. Information collected in May 1995 was not included in the final analysis of the results.

A total of 2400 patients were studied in the six PHC centres in the prospective study. The retrospective study included a total of 12000 patient records and prescriptions. The number of patients studied from different PHC centres before and after intervention and the total number of patients visiting each PHC centre during the period of study are summarized in Table 1.

\section{Statistical methods}

The data were coded, entered and processed on an IBM-PC compatible computer using SPSS (version 6). Frequency distribution was obtained. The Mann-Whitney test was used to ascertain significance differences between the values of two groups pre- and post-intervention for nonparametric data analysis. The level $P<0.05$ was considered the cut-off value for significance.

\section{Results}

Results of the study of prescribing indicators (Table 2) showed that the average number of drugs prescribed per encounter was 2.8 before and 2.7 after intervention. All drugs were prescribed by proprietary names, although they were included in the formulary in their generic names. It was found that $92 \%$ of visits to the health centres resulted in a prescription before intervention and it dropped to $85 \%$ after; the difference was statistically significant. The percentage of prescriptions for antibiotics dropped from $45 \%$ before to $35 \%$ after intervention, which was also statistically significant. The percentage of encounters with an injection dropped from $16 \%$ before to $14 \%$ after intervention, a nonsignificant change.

The average consultation and dispensing times were similar before and after intervention, and $96 \%$ of the dispensed drugs were adequately labelled before intervention, which was almost the same following intervention. A current copy of the PHC formulary of drugs was always available, and $90 \%$ to $91 \%$ of key drugs were available during the period of the study. 
Table 2 Results of the study of drug-use indicators before and after intervention

\begin{tabular}{lcc}
\hline Drug-use Indloator & Before & After \\
\hline Prescribing indicators & & \\
Average number of drugs per encounter & 2.8 & 2.7 \\
Percentage of drugs prescribed by generic name & 0 & 0 \\
Percentage of encounters with an antibiotic prescribed & 45 & $35^{*}$ \\
Percentage of encounters with an injection & 16 & 14 \\
Percentage of drugs prescribed from PHC drug formulary & 100 & 100 \\
Percentage of visits resulting in a prescription & 92 & $85^{*}$ \\
Patient care indicators & & \\
Average consultation time (minutes) & 10.8 & 10.9 \\
Average dispensing time (seconds) & 89 & 91 \\
Percentage of drugs actually dispensed & 100 & 100 \\
Percentage of drugs adequately labelled & 96 & 97 \\
Health facility indicators & & \\
Availability of key drugs (\%) & 91 & 90 \\
Availability of a copy of an essential drugs list or formulary (\%) & 100 & 100 \\
\hline
\end{tabular}

* Statistically significant, $P<0.005$

Individual antibiotics prescribed before and after intervention are listed in Table 3. Antibiotics commonly prescribed were penicillins (most frequently amoxycillin), far ahead of cephalosporins and erythromy- cin. Prescriptions for penicillins dropped after intervention, while erythromycin and cephalosporins prescriptions increased. There were minor changes for other antibiotics

Table 3 Antibiotlce prescribed as a percentage of the total drugs prescribed and as the percentage share (proportionate distribution) of antlbiotics prescribed before and after intervention

\begin{tabular}{lcccc}
\hline Antibiotic & \multicolumn{2}{c}{$\begin{array}{c}\text { Percentage of total } \\
\text { Before }\end{array}$} & $\begin{array}{c}\text { Percentage share } \\
\text { After }\end{array}$ & $\begin{array}{c}\text { Before } \\
\text { After }\end{array}$ \\
\hline Penicillins & 33.40 & 23.45 & 74.0 & 67.0 \\
Cephalosporins & 4.05 & 5.30 & 9.0 & 15.0 \\
Erythromycin & 4.95 & 4.90 & 11.0 & 14.0 \\
Tetracyclines & 0.04 & 0.33 & 2.1 & 0.0 \\
Sulfonamides & 0.86 & 0.56 & 1.9 & 1.6 \\
Aminoglycosides & 0.45 & 0.14 & 1.0 & 0.4 \\
Chloramphenicol & 0.18 & 0.07 & 0.4 & 0.2 \\
Other antibiotics & 0.18 & 0.21 & 0.4 & 0.6 \\
Anti-tuberculosis & 0.09 & 0.09 & 0.2 & 0.3 \\
Total & 45.10 & 35.05 & 100 & 100 \\
\hline
\end{tabular}




\section{Discussion}

Monitoring systems and interventions have been reported to be useful in improving the quality of health care in many countries. Interventions have been shown to change drug-use indicators and other indicators, such as antidiarrhoeal drug use and oral rehydration therapy in different countries $[7,8]$.

In this study, we conducted a survey using the drug-use indicators described by the WHO. To our knowledge this is the first time a survey about the quality of health care and prescribing behaviour has been conducted in the UAE and the effect of an intervention studied.

It is important to note the limitations of this study. The number of PHC centres included represents only the Sharjah Medical District ecntres and a further study concerning the whole country is currently in progress. The study sample was bigger in the retrospective study than the prospective study as it was more convenient to study patient records and prescriptions. The additional indicator, percentage share of each antibiotic, needs to be tested further.

In our study, the average number of drugs prescribed per efcounter and the percentage of encounters with an antibiotic prescription were higher than reported in Yenen, Sudan, Malawi, Bangladesh and several other developing countries [7]. Such prescribing behaviour may be related to both the physician's and the patient's attitude towards patient management.

The values of many of the indicators, such as the percentage of drugs prescribed from the essential drugs list or drug formulary, the percentage of drugs actually dispensed, the avallability of key drugs and the availability of copies of essential drugs lists or formularies were found to be good in the present study. Thus, it would appear that there is no need to expend more resources on these features. There is a clear need, however, to emphasize that prescriptions should be written using the generic names of drugs.

Although it is difficult to give optimum values for consultation time, our study showed that the physicians were able to spend a reasonable amount of time for each patient encounter, much longer compared with the reports in Bangladesh, Indonesia and Nigeria [7]. This may be because of a lower patient:physician ratio in the $\mathrm{PHC}$ centres studied compared with health care facilities in those countries.

The pharmacies in the PHC centres studied are run by trained pharmaclsts with the help of pharmacy assistants. Although the dispensing time appears to be reasonable, most of this time was spent in preparing the medication and labelling. For proper patient care, an appropriate amount of time should be spent by the pharmacist explaining the safe use of the medications to the patients. In the current circumstances, where the pharmacists spend most of their time registering the consumed versus supplied drugs and preparing and labelling the medication, it may be difficult to spare extra time to talk to the patients. Unfortunately, it was not possible to study patient knowledge of correct dosage and patient satisfaction at this stage. A comprehensive study investigating patient perception of the health services, including pharmacy services, is soon to start in the same PHC centres.

Antibiotics are the most commonly prescribed class of drugs and have been reported to account for almost $50 \%$ of the pharmacy budget in hospitals [9]. It is also estimated that in many centres a very high percentage of antibiotics are inappropriate- 
ly prescribed [10]. Common medical conditions in patients in the PHC centres in the IJAF, are upper respiratory tract infections, diarrhoea, skin diseases and lower urinary tract infections. Half of all antibiotics prescribed in the six PHC centres studied were for patients with upper respiratory tract infections and diarrhoea. The effectiveness of antibiotics in many cases of upper respiratory infection is questionable [11].

An insight into factors influencing the prescription of antibiotics may be helpful and contribute to more rational prescription behaviour. Patient education regarding the use and abuse of antibiotics should also be considered as drugs can be easily prescribed or purchased in the UAE. Easy availability of drugs is one of the causes of a high incidence of self-medication in developing countries [12].

The efforts of the ACC had a significant impact on the physicians' prescribing behaviour of antibiotics. The percentage of prescriptions with antibiotics decreased, particularly the most commonly prescribed antibiotic, amoxycillin. Prescription of antibiotics like tetracyclines and chloramphenicol also decreased. Such changes in the prescribing behaviour may be due to reinforcement of the knowledge of the adverse effects of different antibiotics and the availability of relatively safer alternatives.
These results indicate that a high standard has been maintained in several areas in these PHC centres. However, the average number of drugs per encounter, the percentage of encounters with an antibiotic prescribed and the percentage of drugs prescribed by generic name are three areas which need further intervention to improve the quality of health care. Antibiotics use is an area where physicians in the PHC centres can coordinate with a multidisciplinary team, including other health professionals such as pharmacists and microbiologists, for assuring optimum drug use. This study needs to be extended and repeated over time to maintain good quality health care in the PHC centres covered by the study. Furthermore, it is essential to extend the study to cover PHC centres and hospitals in other Emirates of the UAE for investigation of drug utilization throughout the country.

\section{Acknowledgements}

The authors are grateful to Shaikh M. AlQasemi, Director, Sharjah Medical District, members of the Antibiolics Control Committee and the staff of the Pharmacy Department, Sharjah Medical District for their guldance and assistance in this study.

\section{References}

1. Guglielmo BJ, Brooks GF. Antimicrobial therapy. Cost-benefit considerations. Drugs, 1989, 38:473-80.

2. Farrar WE. Antibiotics resistance in developing countries. Lournal of infectious diseases, 1985, 152:1103-6.
3. Hogerzeil HV. Promoting rational prescribing: an international perspective. British journal of clinical pharmacology, 1995, 39:1-6.

4. Marr JJ, Moffet HL, Kunin CM. Guidelines for improving the use of antimicrobial agents in hospitals: a statement by the infectious Diseases Society of 
America. Joumal of infectious diseases, 1988. 157:869-76.

5. Bener A, Abdulla S, Murdoch JC. Primary health care in the United Arab Emirates. Family practico, 1993, 10:444-8.

6. World Health Organization Action Programme on Essential Drugs. How to investigate drug use in healih facilities: selected drug use indicators. Geneva, World Health Organization, 1993 (WHO/ DAP/93_1).

7. Hogerzeil HV et al. Field tests for rational drug use in health facilities in twelve developing countries. Lancet, 1993, 342(8884): 1408-10.

8. Hogerzeil HV et al. Impact of an essential drugs programme on avallablity and rational use of drugs. Lancet, 1989, 1(8630):141-2.
9. Berman JR, Zaran FK, Rybak MJ. Pharmacy-based antimicrobial monitoring service. American journal of hospital pharmacy, 1992, 49:1701-6.

10. Kunin CM. Evaluation of antibiotic ueage: a comprehensive look at alternative approaches. Review of infectious diseases, 1981, 3:745-53.

11. Kuyvenhoven $M$, de Melker $\mathrm{A}$, Van der Velden $K$. Prescription of antibiotics and prescribers' characteristics. A study into prescription of antibiotics in upper respiratory tract infections in general practice. Family practice, 1993, 10:366-77.

12. Kunin $\mathrm{CM}$ et al. Social, behavioural and practical factors affecting antibiotic use worldwide: report of Task Force 4. Review of infectious diseases, 1987, 9 (suppt.3):\$270-85.

Ine regional programme on essential drugs is placing increasing emphasis on promoting local drug industries and strengthening national quality assurance systems. A regional plan for quality assurance of biologicals has been formulated and the programme is also supporting the publication of national documents covering various areas of special importance to the national drug formulary.

Source: The World Health Report 1997. World Health Organization, Geneva. 